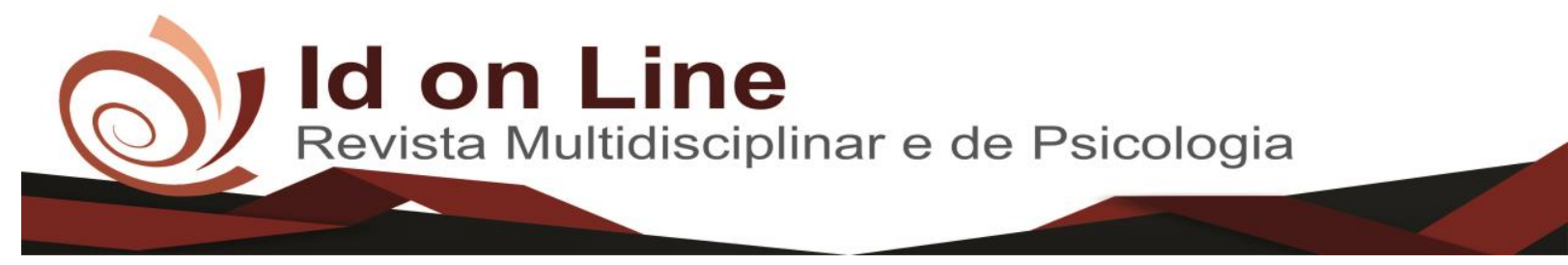

Artigo

\title{
O Convívio Entre Mães e Filhos \\ e a iniciação ao Uso de Drogas
}

Dejanira Aparecida Lacerda Brandão ${ }^{1}$; Luciana de Araujo Mendes Silva ${ }^{2}$; Antônio Junior de Oliveira ${ }^{3}$; Gilmar Antoniassi Junior ${ }^{4}$

Resumo: O objetivo: analisar a relação entre mães e filhos na iniciação ao uso do álcool e outras drogas por parte dos filhos, com pacientes atendidos em um Centro de Atendimento a Dependentes Químicos. Método: Trata-se de um estudo do tipo qualitativo transversal, de natureza exploratória, cuja a amostra foi constituída, aleatoriamente, por conveniência resultante em 11 atendidos. Os dados foram coletados por meio de uma entrevista semiestruturada e aplicação do inventário de estilos parentais. Resultados: Indica que os primeiros contatos com as drogas ocorreram na infância e puberdade-adolescência. A influência dos amigos, familiares e problemas advindos das relações conflituosas são preditores para o primeiro envolvimento. Os vínculos entre mães e filhos são ambivalentes entre a sensação de amparo e desamparo. Conclusão: O sujeito, ao defrontar com situações os quais apontam disfuncionalidades dos fatores que correspondem afetividade e estabilidade emocional, hipervigilância e orientação para o outro, são uma constante ameaça na sua capacidade de ser e estar no mundo, e usam a drogadição como via de recurso único.

Palavras-chave: Drogas. Mães. Vulnerabilidade.

\section{The Convivion Between Mothers and Children and the Initiation of the use of Drugs}

\begin{abstract}
Objective: to analyze the relationship between mothers and children in the initiation of the use of alcohol and other drugs by the children, with patients attended at a Center for Care of Chemical Dependents. Method: This is a cross-sectional qualitative study of an exploratory nature, the sample of which was randomly constituted for convenience resulting in 11 attended. Data were collected through a semistructured interview and the inventory of parental styles. Results: It indicates that the first contacts with drugs occurred in childhood and pubertyadolescence. The influence of friends, family, and problems arising from conflicting relationships are predictors of first involvement. The bonds between mothers and children are ambivalent between the sense of shelter and helplessness. Conclusion: When confronted with situations that point to dysfunctionalities of the factors that correspond to affectivity and emotional stability, hypervigilance and orientation to the other, they are a constant threat in their capacity to be and be in the world, and use drug addiction as a means of resource.
\end{abstract}

Keywords: Drugs. Mothers. Vulnerability.

\footnotetext{
${ }^{1}$ Graduanda em Psicologia. Departamento de Graduação em Psicologia da Faculdade Patos de Minas. Patos de Minas, MG, Brasil. Contato: dejaniralacerda@hotmail.com;

${ }^{2}$ Doutora em Promoção de Saúde e Mestre na mesma área, possui Especialização em Histologia Humana; Especialização em Didática e Metodologia do Ensino Superior, graduada em Biologia. Universidade de Franca, UNIFRAN, Brasil.

${ }^{3}$ Docente do Instituto Federal do Triângulo Mineiro. Patrocínio, MG, Brasil. renatafsantos07@ yahoo.com.br;

${ }^{4}$ Mestre em Promoção de Saúde, Universidade de Franca. Docente do Departamento de Graduação em Psicologia da Faculdade Patos de Minas. jrantoniassi@hotmail.com
}

Autor correspondente: Gilmar Antoniassi Júnior. Rua Maria da Glória G. Mota, 423 - Jardim Panorâmico - 38.705-399 Patos de Minas, MG, Brasil, contato: jrantoniassi@hotmail.com.

512 Id on Line Rev. Mult. Psic. V.12, N. 40. 2018 - ISSN 1981-1179

Edição eletrônica em http://idonline.emnuvens.com.br/id 


\section{Introdução}

Diante dos problemas das drogas que envolvem as famílias, atualmente, o avanço no consumo das drogas tem sido um dilema no âmbito das relações familiares, os usos de substâncias lícitas, principalmente, fazem-se presentes de forma nociva desde a mais tenra idade entre pais e filhos. Evidente, em estudos com gestantes sendo a maioria usuárias de álcool, seguido do tabaco, maconha e crack (MAIA, PEREIRA; MENEZES, 2015). Demonstrando a relação das drogas iniciada no período gestacional.

É preciso compreender que o uso constante e descontrolado das drogas pode comprometer seriamente o funcionamento do organismo, levando a consequências irreversíveis para a mãe e o bebê (MAIA, PEREIRA; MENEZES, 2015). A maternidade não se traduz em apenas ato de possuir um filho e/ou gestar, mas à condição de desenvolvimento ofertada nos cuidados de sobrevivência requerentes ao modo de estabelecer a ligação entre mãe e filho (RAPOPORT; PICCININI, 2011).

No entanto, a maternidade simboliza o estado de mudança de vida, de tempo, pensamento, para a mulher por acomodar e/dar condição de vida a um novo ser que se desenvolve e, logo adiante, possibilitará a ensiná-lo a viver. Exigindo a promoção de cuidados que atenda às necessidades de segurança e de afeto (RAPOPORT; PICCININI, 2011; BATTIKHA, FARIA; KOPELMAN, 2007).

Fato é que para se garantir um bom desenvolvimento, é necessário o acompanhamento das mães expostas ao consumo das drogas durante a gestação e, nos primeiros anos de vida da criança, para manter-se afastados dos riscos ocasionados pela vulnerabilidade do uso (FERRARI; PICCININI, 2010; SILVA; ROCA，2014; FERNANDES; ANTONIASSI JUNIOR, 2016). Filhos de mulheres que fumam maconha, em torno de duas vezes por semana, por exemplo, sofrem de tremores e problemas de sono. Além do mais, estudos sugerem que transtornos de aprendizagem e problemas de atenção como sendo comuns entre crianças expostas à relação materna gestacional e às drogas (BEE, 2011).

Para isso, faz-se preciso compreender que o processo em torno da maternidade está comprometido com a constituição do ser gerido pelo corpo feminino, socialmente concebido pela total responsabilidade da mulher. Originária nas transformações ocorridas pelo corpo grávido, e o universo de significados interiorizados ao longo das experiências vivenciadas em sua vida (FERRARI; PICCININI, 2010; BERGER; LUCKMANN, 2012). O papel do cuidado 
materno é a base da satisfação instintiva, e o cuidado com o recém-nascido é facilmente tido para que tudo possa seguir bem (FERNANDES; ANTONIASSI JUNIOR, 2016; WINNICOTT, 2007).

Neste sentido, é preciso garantir à mulher, ao engravidar, que possa se enxergar como mãe, e, assim, buscar referências na sua própria história de vida, incitar o desejo e tomar para si a representatividade de significar para seu filho, deslocando do lugar de filha para mãe. Ressignificando suas próprias questões enquanto mulher /pessoa para constituir-se aberta e verdadeiramente como mãe (FERRARI; PICCININI, 2010; BERGER; LUCKMANN, 2012; SANTOS; MOTTA, 2014).

Fato notório é que as mães, em suas relações com os filhos estabelecem uma relação de fantasia e expectativa, em que, em cada família, os momentos vivenciados pelos pares são conduzidos por um sistema de crenças, estabelecidos por uma agregação de atitudes, suposições, expectativas, conceitos, preconceitos e convicções (PAPP, 1992; ANDOLFI; ANGELO, 1988). Deste modo, a necessidade de ater-se ao cuidado frente a complexa questão do uso e da dependência das drogas é problema inquietante que atinge a todos de maneira próxima e abrangente. Mostrando, inegavelmente, que o consumo somente tem aumentado e atingido a todos em diferentes níveis e contextos, no entanto, fragilizando mais diretamente aqueles em condição de vida precária e baixa renda(BATTIKHA, FARIA; KOPELMAN, 2007; FERNANDES; ANTONIASSI JUNIOR, 2016).

Estudos revelam que mulheres que vivenciaram problemas com as drogas e/ou condições precárias, buscam na maternidade ações que diferem suas histórias para as histórias de seus filhos, mesmo que na vulnerabilidade. Elas tendem a querer o diferente depositando em seus filhos a esperança de uma relação autêntica de comprometimento com o próximo (BERGER; LUCKMANN, 2012; PAPP, 1992). É preciso ater-se, entretanto, ao fato de que o problema decorrente do uso das drogas não se encontra na tipologia da constituição ou modelo de família, mas na exposição do risco e na proteção que o sujeito evidencia no meio familiar (FERNANDES; ANTONIASSI JUNIOR, 2016).

As falhas maternas que podem ocorrer ao longo do desenvolvimento podem comprometer ou fortalecer o ego do filho; porque, incisivo afirmar que a relação materna é primordial para garantia do bom desenvolvimento. A mãe é, indubitavelmente, o ser capaz de ofertar apoio e suprir as necessidades do filho, de ensinar o caminho de lidar com o desejo e a frustração, alegria e tristeza (BARBOSA, MACHADO, SOUZA; SCORSOLINI-COMIN, 
2010; WINNICOTT, 1983; XAVIER, FERREIRA; PARAVIDINI, 2011). Além disso, o diálogo, as atividades sociais, a condição de oferta à educação, os mecanismos de proteção ao risco e vulnerabilidade dos problemas das drogas são todos assuntos que precisam ser discutidos e pensados quando se fala em consumo de drogas, tanto o uso ocasional, rotineiro e/ou uso intensificado, aquele indicador, inclusive, preditor para a extensão de um problema passado de geração para geração (BATTIKHA, FARIA; KOPELMAN, 2007; FERNANDES; ANTONIASSI JUNIOR, 2016).

É evidente que a dependência de drogas, no contexto mundial, tornou-se uma questão de saúde e não de justiça. Diferentes são os fatores que incitam ao uso, no entanto, o meio em que se vive é um preditor de destaque para a vulnerabilidade do uso das drogas (FERRARI; PICCININI, 2010). Por sua vez, a função materna torna-se referência de amparo ao filho na relação contextualizada no ambiente, neste sentido, o tipo de relação estabelecida é um ponto essencial para a constituição do filho enquanto sujeito (FERNANDES; ANTONIASSI JUNIOR, 2016; ANDOLFI; ANGELO, 1988).

A escolha deste tema, suscitou por perceber a importância da mãe para o desenvolvimento infantil e o reflexo destas relações na vida adulta. Devido as mães transmitirem segurança que permitem trocas afetivas e, desta forma, influenciam o modo de ser e agir do indivíduo adulto.

Para ficar bem claro nesta pesquisa: as mães tornam-se um pilar na construção de vínculos saudáveis ou adoecidos entre seus membros, assim, quando os vínculos são disfuncionais, tais como o uso de álcool e outras drogas, é mais provável que o comportamento dos filhos seja conduzido a uma norma desviante. Também é relevante os fatores genéticos, psicossociais e ambientais dentro do contexto familiar.

O objetivo do estudo corresponde, como já posto, em analisar a relação entre mães e filhos na iniciação ao uso do álcool e outras drogas por parte dos filhos, com pacientes atendidos em um Centro de Atendimento a Dependentes Químicos. 


\section{Método}

O presente trabalho foi desenvolvido por meio de pesquisa de campo, do tipo qualitativo transversal, de natureza exploratória, realizado em um Centro de Atendimento a Dependentes Químicos, de uma cidade da região do Alto Paranaíba, estado de Minas Gerais, Brasil.

Participaram do estudo 20 pacientes, os quais já usaram álcool e outras drogas, e, atualmente, estão em tratamento no Centro. A amostra foi constituída aleatoriamente por meio de conveniência, resultando na participação de 11 atendidos. Foram inclusos aqueles que possuíam idade igual e/ou superior a de 18 anos, que se relacionaram com suas mães biológicas e/ou substitutas, e se propuseram a ser entrevistados. Os exclusos se deram por terem rasurados os instrumentos e/ou por não terem atendido aos critérios de inclusão.

Como instrumentos de pesquisa, utilizou-se da Entrevista Semiestruturada para contextualização da relação materna - álcool e outras drogas - vida, e do Inventário de Estilos Parentais desenvolvido por Jeffrey Young, traduzido e adaptado para a população brasileira por Valentini (2009), composto por 72 itens nos quais os respondentes classificam suas mães segundo uma série de comportamentos, os itens são classificados em uma escala Likert de 6 pontos.

O presente estudo atendeu aos princípios éticos segundo às Resoluções do Conselho Nacional de Saúde $n^{\circ}$. 466/2012 e Nº. 510/2016 para pesquisa com seres humanos, para tanto, foi submetido, através da documentação necessária para análise ética e acompanhamento do Comitê de Ética e Pesquisa da Faculdade Patos de Minas, sob aprovação do parecer $n^{\circ}$. 1.868 .912 .

A coleta de dados ocorreu após a sensibilização do estudo junto aos pacientes da Clínica, em que houve a explicação da proposta da pesquisa. Aqueles que manifestaram interesse em participar foram orientados a direcionar-se a uma sala reservada. Primeiramente, foram-lhes entregue o Termo Consentimento Livre Esclarecido (TCLE) para que tomassem a ciência e conhecimento do estudo, e posteriormente todas as dúvidas fossem esclarecidas, e o termo assinado. Logo após, iniciou-se a entrevista e foram disponibilizados até dois atendimentos de 2 horas para cada participante envolvido, dando a eles nomes fictícios.

Como método de coleta de dados, utilizou-se da entrevista clínica psicológica inicial, que é de extrema importância no que diz respeito à formação das primeiras impressões do paciente e do terapeuta. É crucial no sentido de que é através dessa que se formam as primeiras 
hipóteses diagnósticas. Para Haynes (1978), propõe que, nesta entrevista, ocorra um levantamento de todas as possíveis áreas de problema, e que seja aberta. O mesmo deve ocorrer sempre que se introduzir um assunto novo. O inventário foi aplicado após todos os dados da entrevista terem sido esgotados.

As análises do inventário corresponderam à utilização da padronização do instrumento. Já as entrevistas foram transcritas e analisadas por meio da categorização dos dados em: a iniciação com as drogas - tipo de drogas - envolvimento com as drogas - vínculo - afetividade - tipo de relação parental. A identificação do tipo de relação parental tomou-se como base o Roteiro de Tipologia Familiar, levando-se em conta a identificação da presença das variáveis descritas no quadro 1.

Quadro 1: Roteiro de Identificação da Tipologia Familiar quanto a Relação Parental.

\begin{tabular}{|c|c|}
\hline \multicolumn{2}{|r|}{ MODELO FAMILIAR - RELAÇÃO PARENTAL } \\
\hline Tipo de Família & Características \\
\hline $\begin{array}{l}\text { Família Equilibrada } \\
\text { (estável) }\end{array}$ & Família mostra-se unida e os pais são concordantes e conscientes do seu papel. \\
\hline Família Rígida (instável) & $\begin{array}{l}\text { Família em há dificuldade em compreender assumir e acompanhar o } \\
\text { desenvolvimento saudável dos filhos. }\end{array}$ \\
\hline $\begin{array}{l}\text { Família Super-protetora } \\
\qquad \text { (instável) }\end{array}$ & $\begin{array}{l}\text { Família em que há preocupação excessiva em proteger os filhos, sendo os pais } \\
\text { supercontroladores. }\end{array}$ \\
\hline $\begin{array}{l}\text { Família Permissiva } \\
\quad \text { (instável) }\end{array}$ & Família em que os pais não são capazes de disciplinar os filhos. \\
\hline $\begin{array}{l}\text { Família Centrada nos } \\
\text { filhos (instável) }\end{array}$ & $\begin{array}{l}\text { Família em que os pais não sabem enfrentar os seus próprios conflitos conjugais } \\
\text { que desvalorizam sem avaliação e ajustamento. }\end{array}$ \\
\hline $\begin{array}{l}\text { Família Centrada nos } \\
\text { pais (instável) }\end{array}$ & $\begin{array}{l}\text { Família em que as prioridades dos pais focalizam-se nos projetos pessoais } \\
\text { individuais (profissionais ou lúdicos). }\end{array}$ \\
\hline $\begin{array}{l}\text { Família Sem objetivos } \\
\quad \text { (instável) }\end{array}$ & Família em que os pais estão confusos por falta de objetivos e metas comuns. \\
\hline
\end{tabular}

Fonte: CANIÇO, BAIRRADA, RODRÍGUES; CARVALHO, 2010.

\section{Resultados e Discussão}

O estudo possibilitou identificar que a idade de iniciação ao uso do álcool e outras drogas ocorreram na puberdade, início da adolescência (entre 10 a 14 anos), apenas dois dos participantes indicaram o início do uso com 17 e 18 anos de idade. O álcool foi a droga, entre os entrevistados, de maior consumo, seguido da maconha, cocaína, crack e thinner. 
Quando era criança, meu pai me oferecia a espuma da cerveja. Aos 12 anos, por influência dos meus amigos, passei a fazer uso da bebida, me envolvi com uma mulher mais velha, dependente do álcool, a partir daí, passei a fazer uso sempre do álcool e veio as outra droga. (Sujeito 1)

Eu era criança quando minha avó, mãe da minha mãe bebia vinho e oferecia, eu gostava. Aos 17 ano, comecei a sair com uns amigo aí e eles bebia muito. Fui trabalhar fora, e me envolvi com muita mulher que usava álcool e nunca mais me livrei desse vício. (Sujeito 2)

Comecei aos 12 anos usa bebida alcoólica para acompanha meus colegas, gostei muito do efeito e aos 30 anos perdi o controle. (Sujeito 3)

Iniciei fazendo uso da bebida, aos 14 anos e aos 15 da maconha. Comecei a beber por causa dos problema da vida e das tristeza. A relação dos meus pais era conflituosa. (Sujeito 4)

Em relação à iniciação ao uso das drogas, os dados assemelham-se a estudos com jovens universitários, os quais indicam terem tido o contato com as drogas na adolescência. De modo que o álcool é a droga mais consumida entre as pessoas e presente em diversos contextos da vida, posteriormente, a maconha e as demais drogas (ANTONIASSI JUNIOR; GAYA, 2015a; ANTONIASSI JUNIOR; GAYA, 2015b; FERRO, GAYA, ANTONIASSI JUNIOR, 2014).

É válido ressaltar, neste contexto, que a presença do álcool, no núcleo familiar, faz-se presença constante nas maiorias das famílias, sendo que o uso abusivo de drogas lícitas e ilícitas vem sendo foco de grande preocupação mundial, considerado pelas autoridades em saúde como uma doença crônica e recorrente, com sérias consequências pessoais e sociais para aqueles que usam e não usam (MEDEIROS et. al, 2013).

Percebe-se, no estudo, que a influência dos amigos, familiares e aqueles problemas advindos das relações conflituosas são preditores para o primeiro envolvimento com o álcool, e as outras drogas. A ausência do diálogo e a busca pela aceitação em um grupo social facilita a armadilha do encantamento com a bebida e as demais drogas.

Bebia nas festas de família, escondido de meus pais, tinha 11 anos. Aos 15 anos, meus pais me deixou eu ir para festas de amigos... aí eu podia beber livre. Depois fui morar longe dos meus pais, aí eu frequentava baladas e passei a usar drogas. (Sujeito 5) Eu era muito tímido quando comecei a frequentar festas, comecei a usa a bebida para ter coragem de conversar com as pessoas. (Sujeito 6)

Conforme identificado no estudo, a influência de pessoas do meio/contexto social familiar e/ou escolar - do dia a dia são fatores facilitadores do contato com o álcool e as demais drogas. No que tange ao álcool, a facilidade de acesso e o estímulo constante para o consumo nos ambientes festivos e sociais favorecem e ampliam o consumo, além de agir como 
estimulante para descontração e inibição. Pesquisa com universitários revelam a frequência do consumo do álcool e outras drogas; ocorre, geralmente, na casa de amigos e familiares (ANTONIASSI JUNIOR; GAYA, 2015a; ANTONIASSI JUNIOR; GAYA, 2015b), confirmando, assim, os achados neste estudo.

O fato é que o álcool é a droga de maior consumo entre as pessoas e mais presente entre as famílias nos encontros e festas, bem como nas baladas em geral, configurando a disposição para a condição utópica da felicidade. A sensação de liberdade e euforia provocada pelo efeito do álcool e/ou demais drogas garante a quem usa o poder do autocontrole de suas atitudes. Ao mesmo tempo, a ausência da presença dos pais em vigia funciona como liberdade para uso.

É evidente a necessidade de que as famílias necessitam encontrar mecanismos para entenderem e perceberem a problemática das drogas, estando dispostas a repensarem suas condutas em relação ao consumo do álcool e outras drogas, a fim de evitarem danos futuros (MEDEIROS et. al, 2013).

Convivo com as drogas, desde da minha gestação. Aos 14 anos, comecei com cigarros, aos 15 a maconha, pois era levado pela emoção e pela moda. (Sujeito 7) Desde criança, estou no meio dos usuários de álcool, achava muito animado e divertido estar junto deles. Aos 18 anos a bebida não supria mais minhas vontades, por isso comecei a usar drogas. (Sujeito 8)

É importante salientar a complexidade gerada pela exposição do risco ao convívio com o álcool e outras drogas, quanto presente no meio familiar. A tendência de repetição do comportamento coexistente reflete a influência dos pares para este uso ${ }^{6}$. Os filhos são acarretado pela sobrecarga emocional e os estados de tensão, evidenciados, logicamente, por mudanças comportamentais devido ao agravamento da dependência (MEDEIROS et. al, 2013).

Os achados apontam para a negligência do uso do álcool e outras drogas no núcleo familiar como normal e benéfico, a maiorias das mães dos entrevistados são mulheres que tiveram e/ou tem problemas com o álcool e/ou outras drogas.

Tive uma infância boa, minha mãe sempre fez uso de drogas e participava do tráfico. Nos momentos em que ela estava drogada, eu cuidava dela. (Sujeito 7)

Sai de casa com 8 ano, mas ia sempre visitar minha mãe, que era usuária de bebida alcóolica. (Sujeito 8)

Minha mãe fazia uso de bebida alcoólica e isso fez eu afastar dela por sentimento de raiva. (Sujeito 9) 
É importante destacar, aqui, como a função materna é desenvolvida, enfatizando também o fato de que estas limitações afetarão o funcionamento e a representação para o filho. Assim, a interação que não potencialize o diálogo e a dificuldade do exercício das funções parentais, especialmente a materna, exercida de modo não suficientemente bom, irá refletir de forma negativa na constituição de ser do filho no futuro enquanto adulto - pessoa (RECHIA; SOUZA, 2010).

O estudo aponta para o fato de que os vínculos entre mães e filhos são ambivalentes, entre a sensação de amparo e desamparo. Na maioria das mães, as quais não fizeram uso de álcool e outras drogas, todos os participantes a identificaram com proteção e cuidado. Para aqueles cujo uso de álcool e outras drogas foi / ou é feito, a predominância do desapego e ausência de cuidado é predominante entre os entrevistados, no entanto, entre alguns desses, há ambiguidade de sentimento.

Tive uma infância turbulenta, não criei vínculo com a minha mãe. Nunca ela teve cuidado comigo. Ela dizia que eu não deveria ter nascido, que não devia ter deixado eu nascer. (Sujeito 1)

Sempre me senti amado e protegido pela minha mãe. (Sujeito 2)

Eu sentia estar sozinho desamparado pela minha mãe. (Sujeito 3)

Sempre senti desamparado pela minha mãe, ela não se preocupava comigo; se eu ia voltar; com meus estudos; o que eu fazia. (Sujeito 4)

Eu sentia cuidado e amparado pela minha mãe. (Sujeito 6)

Em vários momentos da minha vida eu senti desamparado, mas eu compreendia a minha mãe. (Sujeito 7)

Nunca senti abandonado pela minha mãe, eu era o preferido... Minha mãe fazia uso de bebida alcoólica, mas sempre era cuidadosa com a casa e com agente. (Sujeito 8) Eu sempre senti bem cuidado pela minha mãe, ela nunca deixou nada faltar para mim. (Sujeito 10)

As complexas interações entre relações familiares interferem na construção identitária do sujeito, uma vez que se percebe este sujeito usuário de droga preso numa relação triangulada com sua mãe, em que na ausência desta mãe, a droga assume papéis parentais, preenchendo vazios na relação conjugal-familiar. Assim, o sujeito necessita sair do contexto familiar, em busca de alívio para a angústia vivida neste cenário e de outras possibilidades para a construção identitária. Neste momento, as drogas são, portanto, a saída encontrada por aqueles para resolver o conflito e amenizar a angústia no âmbito familiar-social-emocional (PENSOC; SUDBRACK, 2009).

Nesta linha de raciocínio, estudos sobre os estilos e práticas parentais de socialização e o consumo de drogas entre adolescentes constatam uma significativa associação entre o 
consumo abusivo das drogas na adolescência a estes estilos e práticas. Os achados apontam a importância de se aprofundar nesta relação mãe-filho para se compreender o consumo abusivo de drogas e as relações familiares (PAIVA; RONZANI, 2009). Em uma quase-ausência de diálogo e fragilidade do vínculo na díade da relação mãe-filho, motivada pelo desequilíbrio e prolongamento da simbiose mãe-filho, há, sem dúvida, uma dificuldade de compreensão do "quem sou eu" dentro do quadro de relacionamentos de diálogos familiares (RECHIA; SOUZA, 2010).

Evidente, em algumas relações, as introjeções do comportamento foram fortes e elas se repetem, como identificado nos achados deste estudo, quando grande parte das mães $(n=7$ fazem uso do álcool e outras drogas) e seus filhos também tiveram envolvimento; confirmando, desta maneira, que os comportamentos têm uma tendência, não rara, a repetirem-se, pelo prolongamento simbiótico.

Em relação ao tipo familiar identificado na análise, pode-se locar todos os envolvidos em famílias instáveis, com perfil rígido, sem objetivo, visto que, conforme definição já expressa anteriormente, o núcleo familiar é centrado nos filhos e configura-se como permissivo.

Sujeito 1 - Mãe era rígida, intolerante, negligente e severa. Não ensinou regras e
limites ao filho. Sentimento de rejeição permeou a relação entre ela e o filho. Mãe
era incapaz de exercer a função materna, deixou faltar os cuidados básicos na
infância. Na adolescência, não houve vínculos que sustentassem a relação entre eles.
Sujeito 7 - Mãe falecida. Foi usuária de bebidas alcóolicas e drogas. Sem estrutura
familiar, sem objetivos, não conseguiu transmitir valores tais como responsabilidade
e ética para o filho. Mãe, sem autonomia e negligente, não conseguiu oferecer os
cuidados básicos ao filho. Mãe era permissiva efoi incapaz de impor limites e regras.
Instabilidade emocional permeava a família tornando o vínculo frágil e enfraquecido.
Sujeito 11 - Mãe não fazia uso de bebida alcóolica. Era afetuosa e cuidadosa, porém
permissiva. Não impôs limites aos filhos para que eles se tornassem capazes de
exercer sua autonomia.
Sujeito 12 - Mãe alcóolatra, negligente, indisciplinada, sem vínculos afetivos, incapaz
de exercer a função materna, desprovida de afetos, permissiva, não estabeleceu
orientações e regras. Ela teve cinco filhos e os entregou para adoção. Conviveu com
a mãe devido a insistência dele, pois foi entregue para adoção por três vezes e sempre
voltava para casa.

Estudos realizados com adolescentes usuários de drogas sobre seus pais revelam que os filhos os quais identificam suas mães como não autoritárias apresentam maior chance de usar drogas, e pais como não autoritários têm mais associação com abuso de drogas BENCHAYA et. al, 2011). 
O papel dos pais na formação dos filhos e nas relações estabelecidas no ambiente familiar influenciam a qualidade da vida familiar em geral e, até mesmo, direcionam a vida do adolescente, podendo funcionar, também, como um antídoto natural contra a toxicomania.

Torna-se importante, deste modo, o desenvolvimento de estudos que busquem caracterizar as relações familiares de drogaditos e não drogaditos, levando em contas variáveis como padrão de consumo e nível socioeconômico dos mesmos, uma vez que dados desta natureza podem contribuir para o desenvolvimento de programas de orientação e de prevenção para pais e para adolescentes a respeito da temática da drogadição (PENSOC; SUDBRACK, 2009; BORTOLON et. al, 2010).

A literatura aponta aspectos do funcionamento familiar, os quais podem atuar como fatores que propiciam o envolvimento com substâncias psicoativas (PENSOC; SUDBRACK, 2009). As representações sociais formuladas pelos familiares podem contribuir para chamar a atenção para os impactos da dependência química, que pode causar não somente à vida dos usuários, mas também à dos seus familiares, devido à sobrecarga advinda do papel do cuidador (MEDEIROS et. al, 2013).

Os estilos maternos identificados apontam disfuncionalidade dos fatores correspondentes à afetividade e à estabilidade emocional, à hipervigilância e à orientação para o outro, à superproteção e à autonomia prejudicada e aos limites prejudicados.

Sujeito 2 - Mãe era afetuosa e cuidadosa, não fazia uso de bebidas alcóolicas ou drogas, porém era submissa ao marido. Tinha instabilidade emocional devido aos conflitos conjugais. Não impôs limites ou regras aos filhos, deixou essa função para o marido e para sua mãe.

Sujeito 4 - Mãe não fazia uso de bebidas alcóolicas. Foi provedora de cuidados e afetos. Não percebeu os conflitos vivenciados pelo filho. Como ela era permissiva, não o orientou e não impôs regras, resultando no filho a falta de autonomia

Sujeito 8 - Mãe alcóolatra, viúva e desprovida financeiramente. Como ela era sozinha, houve dificuldades no desempenho de seus papéis, especialmente no que se refere à conciliação entre sua função de autoridade e a função de provedora de afetos. Após a viuvez, ela buscou satisfazer seu próprio prazer. Ela foi uma mãe permissiva, deixando que o filho buscasse sobrevivência fora do lar e sem cuidados maternos.

Para o entendimento do conceito de dependência química, é importante salientar, para melhor lidar com o familiar dependente, pois a maioria dos familiares apresentaram comportamentos e/ou atitudes codependentes, que a dependência de drogas é um fenômeno que atinge não somente o usuário, mas também o sistema familiar como um todo (BORTOLON et. al, 2010). 
O estudo realizado com famílias de Portugal e EUA confirma a relação de vinculação como sendo um fenómeno universal, não dependendo de variáveis de natureza social e/ou cultural. Logo, constatou-se que a qualidade da vinculação à mãe está positivamente relacionada com todas as dimensões da competência social (a motivação social, os atributos psicológicos e a aceitação social). Os resultados sugerem que a segurança da vinculação está associada a um funcionamento social mais adaptado ao ser promotora de expectativas sociais mais positivas. Assim, pode-se entender que crianças com melhores vínculos maternos desenvolvem adequadamente suas competências sociais; esta relação segura gera expectativas melhores sobre o contexto social, possibilitando, desta forma, melhor adaptação ao filho (VERISSIMO et. al., 2011).

\section{Considerações Finais}

As pessoas nascem como seres desamparados, daí a necessidade do outro para nossa sobrevivência. Daí a importância dos primeiros cuidados oferecidos pela mãe a fim de satisfazer as necessidades de afeto, cuidado e proteção nos primeiros anos de vida, pois, neste ínterim, a criança acredita que ela e a mãe são um ser só. É que, através desta interação "mãe e bebê" que se desenvolve a subjetividade e individualidade de cada um ao longo das experiências de vida. Neste contexto, o estudo evidencia a falta destes cuidados ao longo das experiências vivenciadas entre mãe e filho - no contexto familiar, principalmente, a precariedade e empobrecimento de investimentos da figura materna na representação sistêmica do papel da mãe.

Observa-se, também, dados em que os filhos ficaram susceptíveis às drogas e ao álcool no final da infância e início da puberdade - adolescência, momento crucial para o desenvolvimento na introjeção de valores - normas - condutas. Além do mais, é na adolescência em que a pessoa está mais vulnerável e em busca de inúmeras respostas de si e para si, que se nota a importância do afeto e proteção para fortalecer a sobrevivência física, psíquica e social deste sujeito e que poderia se afastar e ir de encontro com às drogas.

Os resultados deste estudo revelam que estes sujeitos, exatamente quando estavam na busca para suas incompletudes, depararam-se com os conflitos e situações de vivências traumáticas, as quais resultaram em um aniquilamento das condições do ser e estar no mundo 
- e buscaram as drogas. Sendo notórias, portanto, constâncias de instabilidade, fragilidade e precariedade de mecanismos de recursos que se foram acumulando em frustrações. Surgiram então, consequentemente, as lacunas as quais abriram possibilidades não saudáveis de lidar com elas e desafiá-las no uso das drogas.

Neste sentido, percebe-se que o sujeito, ao defrontar com situações descritas nos estilos maternos, os quais apontam disfuncionalidades dos fatores que correspondem à afetividade e estabilidade emocional, hipervigilância e orientação para o outro, à superproteção e autonomia prejudicada e aos limites prejudicados, sendo esses uma constante ameaça na sua capacidade de ser e estar no mundo, ele usa a drogadição como via de recurso único na solução de escapar da sua dor psíquica, tornando seu existir um composto de sofrimento e aprisionamento. Embora cada um, devido à sua individualidade, e dependência por diversas razões e por caminhos singulares, a toxicomania configura-se como um sintoma proveniente das relações conflituosas no âmbito familiar e, principalmente, na relação do filho com a mãe usuária.

É válido ressaltar que, neste estudo, há limitações de alcance da realidade, considerando que sua elaboração foi em dados qualitativos, são falas de pessoas e, nem sempre, refletem a realidade em sua totalidade. Diante disso, a realização de novas pesquisas faz-se necessário para que se busque o avanço na estruturação do conceito de vulnerabilidade nas relações entre mães e filhos que fazem ou já fizeram uso de álcool e outras drogas.

\section{Referências}

ANDOLFI, M.; ANGELO, C. Tempo e mito em psicoterapia familiar. Porto Alegre: Artes Médicas, 1988.

ANTONIASSI JUNIOR, G., GAYA, C. M. Implicações do uso de álcool, tabaco e outras drogas na vida do universitário. Revista Brasileira Promoção de Saúde, vol.28, n.1, p.67-74, 2015a.

ANTONIASSI JUNIOR G.; GAYA, C. M. O uso de droga associado ao comportamento de risco universitário. Revista Saúde e Pesquisa, vol.8, Ed. Esp., p.09-17, 2015 b.

BARBOSA, F. A., MACHADO, L. F. V., SOUZA, L. V.; SCORSOLINI-COMIN, F. Significados do cuidado materno em mães de crianças pequenas. Barbarói, vol.33, n.3, p.28-49, 2010. 
BATTIKHA, E. C., FARIA, M. C. C.; KOPELMAN, B. I. As representações maternas acerca do bebê que nasce com doenças orgânicas graves. Psicologia Teoria e Pesquisa, vol.23, n.1, p.17-24, 2007.

BEE, H. A criança em desenvolvimento. 12ª ed. Porto Alegre: Artmed, 2011.

BENCHAYA, M. C. et. al. Pais não autoritativos e o impacto no uso de drogas: a percepção dos filhos adolescentes. Jornal de Pediatria, vol.8, n.7, p.238-44, 2011.

BERGER, P. L.; LUCKMANN, T. A construção social da realidade. Tradução de Floriano de Souza Fernandes. Petrópoles: Vozes, 2012.

BORTOLON, C. B. et. al. Avaliação das crenças codependentes e dos estágios de mudança em familiares de usuários de drogas em um serviço de teleatendimento. Revista AMRIGS, vol.54, n.4, p.432-36, 2010.

CANIÇO, H., BAIRRADA, P., RODRÍGUES, E.; CARVALHO, A. Novos tipos de família plano de cuidados. Coimbra (PT): Imprensa da Universidade Coimbra, 2010.

FERNANDES, L. M. S.; ANTONIASSI JUNIOR, G. Drogas e a Família, uma discussão da literatura. Revista Psicologia Saúde Debate, vol.2, Ed. Esp., p.73-85, 2016.

FERRARI, A. G.; PICCININI, C. A. Função materna e mito familiar: evidências a partir de um estudo de caso. Revista Ágora, vol.13, n.2, p.243-57, 2010.

FERRO, L. R. M., GAYA, C. M.; ANTONIASSI JUNIOR, G. A violência e o consumo de drogas entre universitários. Brazilian Journal of Forensic Sciences, vol.3, n.3, p.258-272, 2014.

MAIA, J. A., PEREIRA, L. A.; MENEZES, F. A. Consequências do uso de drogas durante a gravidez. Revista Enfermagem Contemporânea, vol.4, n.2, p.121-28, 2015.

MEDEIROS, T. K. et. al. Representações sociais do uso e abuso de drogas entre familiares de usuário. Revista de Psicologia e Estudos, vol.18, n.2, p.269-79, 2013.

PAPP, P. O processo de mudança: uma abordagem pratica a terapia sistêmica de família. Porto Alegre: Artes Médicas, 1992.

PAIVA, F. S.; RONZANI, T. M. Estilos parentais e consumo de drogas entre adolescentes. Revista Psicologia e Estudos, vol.14, n.1, p.177-83, 2009.

PENSOC, M. A.; SUDBRACK, M. F. Envolvimento em atos infracionais e com drogas como possibilidades para lidar com o papel de filho parental. Revista de Psicologia USP, vol.15, n.3, p.29-54, 2009. 
RAPOPORT, A.; PICCININI, C. A. Maternidade e situações estressantes no primeiro ano de vida do bebê. Revista de Psico-USF, vol.16, n.2, p.215-225, 2011.

RECHIA, I. C; SOUZA, A. P. R. Dialogia e função materna em casos de limitações práxicas verbais. Revista de Psicologia e Estudos, vol.15, n.2, p.315-23, 2010.

SANTOS, K. D.; MOTTA, I. F. O significado da maternidade na trajetória de três jovens mães: um estudo psicanalítico. Revista Estudos de Psicologia, vol.31, n.4, p.517-25, 2014.

SILVA, M. K. P.; ROCA, C. R. O reflexo da violência praticada pelas mães no período gestacional contra seus filhos. Inl: XI Seminário Internacional de demandas sociais e políticas públicas na sociedade contemporânea. VII Mostra de trabalhos jurídicos científicos. Santa Cruz do Sul, Brasil: EDUNISC, 2014.

VERISSIMO, M. et. al. A relação entre a qualidade da vinculação à mãe e o desenvolvimento da competência social em crianças de idade pré-escolar. Psicologia Reflexão Crítica, vol. 24, n.2, p.292-299, 2011.

XAVIER, R. B. T., FERREIRA, C. V. L.; PARAVIDINI, J. L. L. Adolescentes em conflito com a lei: função materna e a transmissão do nome do pai. Revista Mal-estar Subjetividade, vol.11, n.1, p.41-64, 2011.

WINNICOTT, D. W. O Ambiente e os processos de maturação: estudos sobre a teoria do desenvolvimento emocional. Porto Alegre: Artmed, 2007a.

WINNICOTT, D. W. O ambiente e os processos de maturação: estudos sobre a teoria do desenvolvimento emocional. Porto Alegre: Artmed, 1983b.

\section{Como citar este artigo (Formato ABNT):}

BRANDÃO, Dejanira Aparecida L.; SILVA, Luciana de A. M.; OLIVEIRA, Antônio Junior de; ANTONIASSI JÚNIOR, Gilmar. Convívio Entre Mães e Filhos e a iniciação ao Uso de Drogas. Id on Line Rev.Mult. Psic., 2018, vol.12, n.40, p.512-526. ISSN: 1981-1179.

Recebido: $13 / 04 / 2018$

Aceito: $26 / 04 / 2018$ 